\title{
Using the (im)materialities framework to trace the contrapuntal lines of allegiance and belonging for globally mobile children.
}

Jeanette Hannaford

Griffith Institute of Educational Research, Griffith University, Australia

This paper discusses the use of Burnett, Merchant, Pahl \& Rowsell's (im)materiality literacy analysis framework to explore online and offline literacies in the lives of globally mobile children. The voices of these children have been little explored in New Literacies research. Globally mobile 'third culture' children who attend International Schools are often foreigners where they live, yet have multiple sites of belonging, including some found in digital worlds. In analysing the abundant data of a year-long multicase study, the theoretical lenses of spatiality, mediation, materiality and embodiment, as proposed in Burnett el al's framework, provided a productive framework through which to explore the complicated intersections of literacy, identity, and digital worlds in these children's lives. The paper demonstrates how the framework might be applied, focussing on two of the children in the study. Prompted by insights provided by the (im)materiality framework, a contrapuntal metaphor is proposed as a way to understand allegiance and belonging in the lives of these globally mobile children.

Keywords: (im)materiality analysis framework, globally mobile children, digital worlds, identity, literacy, belonging, International Schools

Griffith Institute of Educational Research

Mt Gravatt Campus, Griffith University

QLD 4122, Australia

$+19178473884$

j.hannaford@griffith.edu.au 


\section{Introduction:}

This reports on a year-long multicase study carried out in an English-language International School. Twenty children aged between 8 and 13 years from a range of national backgrounds, most of whom had undertaken multiple international relocations, were the focus of the research. The research, positioned within a New Literacies paradigm, aimed to investigate how this particular group of children negotiated the diverse range of discourses they encountered in their in-school and outof-school experiences. During the research process several analytical framings were considered while looking for an effective way to discuss the intricacies of these children's lives.

Well into the initial stages of data analysis, Burnett, Merchant, Pahl \& Rowsell's (2014) (im)materiality literacy framework was published. This framework seeks to highlight the 'complex and diverse relationship between the immaterial and material' (p.90) within meaning-making processes. To do this it proposes a multi-dimensional analysis from and across the concepts of spatiality, mediation, materiality and embodiment. Building a range of readings of the data from these perspectives provided a compelling way of framing and managing the abundance and intricacy of the dataset. It allowed me to look across both single cases, and the whole research space, as examples of 'baroque complexity', in which it is understood that there are no consistently stable patterns (Kwa, 2002; Law, 2004). Importantly, the framework assisted with building a rich picture of these children's experiences, foregrounding their individual voices. 
Burnett et al. (2014) demonstrate the affordances of their framework using examples taken from within one classroom and one lesson. In this paper I provide a brief glimpse of the potential of the (im)materiality framework for structuring analysis across broader spatial and temporal boundaries. Drawing from two of the case-studies, this paper uses the four propositions of the framework to discuss and analyse data referencing different times and locations in these two children's lives. This brings into focus the ways in which these children draw from and position themselves with regards to the various complex, sometimes competing, messages they must manage with regards to cultural subjectivities. Kwa's notion of baroque complexity, which Burnett et al (2014) use to illustrate the complexity of literacy practices that the (im)materiality framework seeks to illuminate, is borrowed as a literal reference in the conclusion. The multiple contrapuntal melodic lines that shape Baroque music are used as a metaphor for the multiple lines of allegiance and belonging found in these children's experiences. As I commenced my career as a secondary school music teacher, this musical metaphor struck me immediately on reading Burnett et al's (2014) referencing of the Baroque. I was delighted to later learn that Edward Said had also recognised the applicability of a contrapuntal metaphor to illustrate the embracing of human diversity, and that the usefulness of Said's use of this metaphor continues to be recognised (Bilgin, 2016; Said, 1984, 1993; Symes, 2006).

\section{Theoretical Framing:}

Presented under the banner of New Literacies to distinguish it from traditional, skillsbased definitions of literacy, this paper is written from a theoretical understanding of literacy(s) as social practice. This understanding sees literacy(s) as meaning-making and communicative processes shaped by the specific spatial and temporal contexts in 
which these processes occur, in interaction with materially and immaterially copresent people, things, signs and tools. Within broad understandings of literacy(s) as social practice, multiple conceptual theories and analytical paradigms exist. In this journal in 2014, Burnett, Merchant, Pahl \& Rowsell wrote of undertaking multiperspective analyses as a means to delve into the complexities of literacy practices. The framework they proposed:

draws attention to the significance of relationships between space, mediation, materiality and embodiment to literacy practices. This in turn emphasises the importance of the subjective in understanding how different locations, experiences and so forth inflect literacy practice (Burnett et al, 2014).

The following paragraphs briefly outline the conceptual theories underlying each of the propositions from which the (im)materialities framework is built.

\section{Spatiality}

This perspective focuses on space as a constitutive element of literacy practices rather than merely a setting for them (Leander \& Sheehy, 2004; Mills \& Comber, 2013). It developed from a socio-geographic understanding of space and spatial processes as distinctive, hybrid and fluid (Lefebvre, 1991; Soja, 1996). The notion of the 'virtual spaces' of the Internet reinforces this idea of space as: perceptual rather than tangible, socially constructed, and a constitutive part of the literacy practices found within it. Particular spatial environments, both virtual and physical spaces such as classrooms, interplay in how understandings are built (Burnett, 2014). Space changes in ephemeral micro-ways (Burnett, 2014), changes that are frequently sociallyconstructed by and through power-ful literacy practices (Comber, 2015).

\section{Mediation}


This theoretical framework for investigating literacies foregrounds the ways in which meaning-making is achieved through the manipulation of the signs and language symbols used to represent things and communicate messages. These semiotic resources are in constant change - in recent decades, much of this change has occurred through and around the rapid development of digital technologies. Through differently mediated literacy practices, ways of thinking about and acting in the world are augmented (Hall, 2013; Kress, 2003). Different semiotic resources may contribute to any single event or text, each individual mode and medium having different affordances and constraints. Further to this, the combination of, and ways in which different modes and media are combined, impacts upon meaning-making experiences (Kress \& van Leeuwen, 2006).

\section{Materiality}

Material 'stuff' forms an important part of our experience in the world, and how we express ourselves in the world (Miller, 2008, 2010). Theoretical approaches that explore materiality within literacy practices may decentralise human actors, instead positioning materials, bodies and texts as equal contributors in meaning-making events. For children on the move, stuff must frequently be divided into stuff that travels with them, like clothes and favourite toys, and material that must be physically left in place, such as the window seats that children have gazed out at the world from, and the playground and sporting structures that have been an integral part of their social lives and sense of self. Immaterial traces of these material things now left behind, may continue to play a role in the child's understandings and ways of being. Things can provide a 'connecting piece - they move, they travel across home and school, and these movements provide power to students’ (Pahl \& Rowsell 2010 p.3). 


\section{Embodiment}

Mills (2015) argues for a greater acknowledgement of the multisensoriality of literacy practice and gives examples of social and cultural forms that draw deeply on embodied literacies, such as sporting activities, artistic endeavours and many occupational duties. One dimension of embodied meaning-making is (the many facets of) emotion. An example of this is the emotional 'ride' imposed by gripping narratives in games, literature and films (Lemke, 2013). Burnett et al (2014) write of this kind of text+embodied response as an example of an (im)material relationship. Emotion affects meaning-making in ways that are relative and interpretive - for example in response to phenomenological changes such as sounds, smells and the quality of light (Pink, 2011). Any individual literacy event or text draws upon embodied subjective understandings in its creation (Burnett et al. 2014). And any reading of a literacy event or text draws upon the reader's perception of felt experience by the text's creator, and ongoing perceptions about the emotional state of co-present others, intertwined with the reader's own immaterial traces of felt experience. The next section gives a generalised account of the life experiences of the globally mobile children in this study.

\section{Globally Mobile Children:}

The school in which the research was carried out follows a historical model, the International Schools established from the 1920s to cater for the children of diplomats and the then-developing transnational and/or non-governmental organisations (Hayden, 2011, 2012; Walker, 2012). A significant number of the children's parents are employed by United Nations affiliated organisations, and are on secondment from 
national regulatory bodies and universities, often in travelling posts as various kinds of scientific experts. The children who attend the school benefit from varying degrees of economic and social advantage, yet due to the mobility that may be inherent to their parent'(s) employment, many of the children manage 'disrupted lifestyles, frequently changing friendships, linguistic challenges and ambivalence about a clear sense of belonging and home' (Hayden, 2012, p73).

In the 1960's anthropologists Useem \& Useem applied the label 'third culture' to the experience of a community of American ex-patriots, suggesting that they formed 'tiny yet vital links between Western and non-western worlds' (Useem et al., 1964, p.17). This led to a literature developing around the experiences of 'Third Culture Kids' (TCKs), and the implications of this kind of childhood in later life (for example, Pollock \& van Reken, 2009). While I draw upon theories within this literature, in order to resist unhelpful restrictive and essentialising definitions of the children I am speaking about, I favour the use of 'globally mobile children' as a broad, loose term to group together the children I write about. Children who identify themselves as the kinds of people who move. Children who have a tendency to construct narratives to relate their life histories through the stages of their moves (Sears, 2011).

In discussions with a group of TCKs, Sears observed that the question 'Where are you from? (...) necessitated on the part of the students a full account of their relocation history', and that the archetypal answer to the question was, 'How long have you got?' (pp.80-81). The narratives then offered, appeared to provide the children with 'a means of making sense of their multiple attachments and experiences' (ibid), and did not necessarily emphasise the family's country of origin. One example Sears gives is of 
twins who answered the question 'where are you from?' differently, one naming the family's country of origin, the other a place where they had had a long and happy posting. Nette \& Hayden explored TCK's perceptions of what it means to belong to a home country and suggested that while the children did have a 'sense of belonging', they had difficulty 'identifying a specific place of belonging' (2007, p. 442).

This paper considers globally mobile children's relationships to home, with 'home' defined as multiple sites of allegiance and belonging. For clarity, an upper/lower case $\mathrm{H} / \mathrm{h}$, is used to distinguish between Home as a family's country of origin, a national, passport-accessed place, and home as the (current) key-accessed space where the children eat, sleep and interact with their families. Whilst these are separate sites, there is a blurring of boundaries between them, and, culturally-complex and co-constructed, H/homes operate within continual processes of change. As is foregrounded in the (im)materialities framework, $\mathrm{H} /$ homes are infused with material and immaterial elements in ways that are intricate and co-dependant. The following table separates some of these elements to serve as a simplified example of Home/home distinctions. Connections can be made across many of these elements.

Insert Table $1 \quad \mathrm{H} / \mathrm{home}$

In an immediate and material sense, home is the place, such as an apartment, to which these children return to rest and replenish. Beyond the four walls and furniture that form the rudiments of a home, are other material objects that are significant components of 'the whole system of things' (Miller, 2010, p. 53). Immaterial components of $\mathrm{H} /$ home can include emotional security, a sense of belonging and 


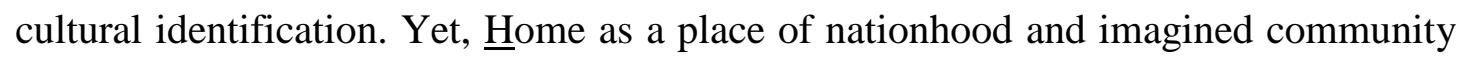
(Anderson, 1983) can be constituted particularly problematically for globally mobile children. It may refer to the country in which a child's parents were born rather than the child. Or, like the twin from Sears' research, a child may develop a lasting attachment to a country in which the family relocated for work and became settled, even if no 'official' ties remain. These attachments may be constantly in flux, as are the illusory understandings of national culture that take shape to underpin them (Anderson, 1983).

\section{Methodology:}

The research was grounded in an understanding of literacy as social practice, foregrounding the importance of actors (broadly understood) and their actions. Within this view, the children's school literacy practices and home literacy practices and play actions were all seen as important components of their literate selves. I set out to know more about how the children negotiate and draw upon the diverse range of discourses they encounter across the different aspects of their lives: from their family in their homes, from friends in out-of-class hours, within the ideologies disseminated at school, and via the media they accessed through digital pathways.

Devised as a multiple case study, and held over the course of a school year, children were recruited from Grades $3-6$ inclusive at a large International School located in a major European city. The twenty participating children were interviewed twice. These interviews centred on their home life and experiences as globally mobile children, their school life, and their play experiences and use of leisure time. Interviews with teachers and parents encompassed similar themes of home, school and media, and 
were called on as background data. The children were each given a journal to be used during the year as a differently mediated means of sharing information about their experiences. Different children used the journals in different ways, but their content often recorded at-home play experiences involving digital technologies.

As many of the children were still in the early stages of their development as writers, the journals were not introduced as important documents in themselves. Some of the children drew in their journals, and during analysis the individual elements of these images were itemised where possible, to assist in reading the images as visual 'statements' remediating experience (Kress \& van Leeuwen, 2006). However, the main role the journals played was as a means of guiding the conversation during 'chats' held each week with each individual child. These chats proved a very satisfactory means of enabling a continuing connection with each child to be maintained over the course of the year. And as aide-memoires accompanying these chats, the journals shifted the power dynamics between adult and child to some extent.

Two different types of field observations were undertaken, in-class during the school day, and observations made during after-school grade-level computer clubs that were especially convened as a part of the study. During these clubs the children played freely in their own choice of digital worlds. Recordings made during the in-class and after-school observations, and the chats and interviews, were then transcribed. These transcriptions, along with field notes and screenshots made during these times, and photographs of the children's journal entries, were sorted into topic files. Increasingly meta-links across many topic files were identified, and the data was eventually 
reclassified into three main clusters of ideas: technology, home, and gender. This paper calls on ideas from the cluster of ideas entitled $\mathrm{H} /$ home to illustrate the ways in which the (im)materialities framework was applied.

\section{Data Analysis}

The analysis needed to make it possible to consider each of the cases as a separate, complex, self-contained entity, as well as allowing ways to view how the cases might be enmeshed (Stake, 2006). A number of different approaches were trialled before Burnett et al.'s (im)materiality framework (2014), was selected. Through the analytical breadth that the four-part framework offered, it was possible to conceptualise a complex and textured sense of the children's lives. The numerous interactions between these four analytical perspectives offer rich understandings. Yet, each and any literacy event can be looked at singly through the lens of any one of the four different proposals, as outlined in Table 2:

Insert Table 2: (Im)materialities Framework (Burnett et al. 2014 p.93)

Spatiality, as presented in Proposition 1: relationships between the material and immaterial are relevant to how literacy is spatialised, had a particularly strong significance for this dataset. Concepts of space within the context of human global mobility are particularly infused with a sense of the local/global relationship not as a stark interface, but as a cross-flowing current. Not only immediate spatial settings needed to be considered, but the number of environments each globally mobile child had experienced, and which were immaterially present in the children's understandings of any individual event/location. In the lives of these globally mobile 
children the world is a more spacious place than it perhaps is for children who have not travelled far or often or for extended periods of time.

When thinking of these diverse spaces, mediation, which forms the second proposition of the analytical framework, Proposition 2, screen-based texts mediate reality in ways that prompt shifting relationships between the material and immaterial, was useful in considering how, for example, social experiences carried out face-to-face, or via technologies like Skype, or between avatars in digital worlds, might differ from each other, even as they worked together to enable fluid social practices in a child's life. Immaterial responses to people and to play became mediated through words and images and materialised in the children's journals. Some children recorded play in playful ways, creating quizzes, hand-drawn 'screenshots' and elaborate annotated 'landscapes’ detailing scenes from birthday parties.

Journals considered as artefacts also become an avenue for considering Proposition 3: Literacies are materialised in things. I was inclined to call upon the lens of materiality most naturally in the children's discussions and documenting of their home spaces. Although interactions with material objects were recorded during classroom observations they were noted in a different way and perhaps to a lesser degree. In the computer club, which was held in the secondary school computer lab, this seemed even more accentuated. The younger elementary school students positioned themselves as guests within this space. They used the objects found within the temporary, foreign environment, but rarely brought their own possessions into the computer labs or marked some sense of ownership. This created a quite different 
materialised environment from their 'home classroom', which promoted thinking about the close relationship between $\mathrm{H} /$ home, things, and belonging.

The lens of embodiment, drawing from Proposition 4: meaning-making is embodied, was also particularly suited to analysis of the children's discussions of their life outside of the school space. Stories here sometimes related to significant events, but also included the everyday experiences of simply being outside surrounded by nature, relaxing at home with family members, or being involved in sporting activities. These everyday stories could sometimes be analysed for less noticeable, more compliant ways of being. In this way they played a key role in considering some of the deeper questions about identity and subjectivity that exist within the research, for example delving into conversations around how a child might 'feel' as a footballer, or as an English person, or as a girl. In what follows I provide more specific examples of how I called upon the (im)materialities framework in the analysis of the children's experiences.

\section{Two case studies:}

In this section two children are discussed, Rania and Edward, yet any of the twenty case studies might have been selected as examples. To some degree, these two were chosen because both children came from families in which maintaining extended family allegiances appeared to be important considerations for their parents. These children were therefore interesting to think about in the context of TCK theories of allegiance and belonging. Each component of the (im)materialities framework illuminated different aspects of the H/home allegiances in these children's lives. 


\section{Rania from Bangladesh}

Rania enjoyed her weekdays at school. Our chats were often about the social worlds of her Grade 4 classroom, and also her life at home. Her father was away for long periods of time on mission to other countries. Rania spoke English with her elder sister and Bengali with her mother (who didn't speak English). At the commencement of her Grade 4 year, Rania attended lessons in Bengali and on the Koran (which included Arabic tuition) on Saturdays. These were held at the mosque her family attended.

Proposition 1 of the (im)materialities framework, 'relationships between the material and immaterial are relevant to how literacy is spatialised', offered up productive ways to think about the different spaces in which Rania was a student, and how these spaces might contribute to her sense of self with regards to cultural belonging. In her International School classroom, Rania was immersed in an inquiry-based curriculum, enacted through play-oriented literacy events. Rania’s learning within the space of the mosque was delivered through different pedagogies. From her perspective, "the teacher keeps telling us what to do. (...) We wrote already our letters that she told us. She says to do them again. Again! Again!". These Saturday events, less welcome than her International School learning experiences, appeared to render the spaces of the Mosque unpleasant to her. Only after the family returned from their biennial visit to Bangladesh in the New Year break, did Rania begin to have success in obtaining her wish to stop her lessons in the mosque. It is likely that it was important to Rania's parents to demonstrate the family's ongoing Islamic connection when they visited their extended family in their Home country. Yet Rania showed no indication that her Saturday lessons were events connected to an (im)material cultural space to which she 
might belong.

The (im)materialities framework, through its focus on space, assisted in the analysis of Rania's conversations around learning at school and in the mosque, and the recognition of the ways in which these different spaces may have contributed to Rania's subjective positionings around her cultural identities. Learning to communicate in a specified language, to build ownership of the cultural worlds that specific language opened up, was a shared ambition of both of Rania's official learning spaces. Yet these were realised in different ways in her regular classroom and the mosque she attended on Saturdays, with the result that these different spaces, in turn, influenced the ways in which Rania positioned herself with regards to her national and cultural subjectivities. Responding to a question about reading the Koran, Rania once told me '(a)ctually I can read it (...) but I don't understand cause I'm not Arabic-ish'. While Bangladesh is a Muslim-majority society, and Islam was her family's religion, for Rania it seemed that these H/home allegiances did not sit comfortably.

Mediation, which forms the second proposition of the analytical framework, Proposition 2, screen-based texts mediate reality in ways that prompt shifting relationships between the material and immaterial, was a different lens through which to view Rania's cultural positionings. Based on her play in digital worlds, Rania made a series of entries in her journal on the theme of Halloween. In the first of these entries she described a dress-up game called Halloween Fairies. The notion of Halloween Fairies in itself seems slightly culturally incongruous. Fairies are not typically used as figures representing horror and death, and Rania described this 
virtual space as 'pretty'. In her remediation of an experience in a virtual space, the sweeping gesture of her final phrase, 'for a background I did stars everywhere', materialised through Rania's journal the imaginative joyful play she found in this virtual space. It appeared that globally mobile Rania had felt comfortably 'at home' in this digital world.

Keeping with the Halloween theme, the next page of Rania's journal contained a hand-drawn facsimile of an online game featuring pumpkins. This literal remediation of a virtual gaming space as a two-dimensional image included a rectangle containing the words 'play again' in the top corner. The third and final of these themed journal entries was presented in the manner of a report on Halloween, perhaps showing traces of Rania's school's focus on writing through genre. This entry, seen below in Figure 1, was illustrated with a small drawing of a bat and a sweet, in keeping with the Halloween theme.

Insert Figure 1: Extract from Rania's Journal

However, other elements of the text seem less straightforward, and this dimension of the (im)materiality framework helped me to consider the complexity of the ways in which Rania was thinking about and positioning herself into available cultural worlds. In this text, Rania constructs for herself a knowingness of Halloween, despite her lack of a lived experience of the festival. She describes 'treaker treating' (sic), as 'going to people's houses to ask for sweets', but also writes that 'children go to people's houses and sing a song to give them pudding'. In this sentence it appears that Rania has confused contemporary American Halloween celebrations with Christmas traditions 
from Britain less popular in current times. Rania learnt Christmas carols in her class music lessons and in the school choir, and was familiar with 'We Wish You a Merry Christmas' and its lyrics documenting the tradition of carolling door to door and its reward of figgy pudding.

In Rania's report she appears to incorporate traces of both the Christmas carol she has learnt in school and the Halloween themed games found in her online play, resulting in her own interpretation of them - a (unintentional) cultural mash-up, then materialised through the differently mediated text of her journal. Halloween and Christmas are unlikely to be emotionally significant celebrations in Rania's family home, if they are celebrated at all. However, through their newly mediated appearance in her journal, Rania plays with the wide range of cultural offerings she observes around her and perhaps begins to stake a claim on these traditions for herself. Through her experiences playing in digital worlds, Rania's ways of thinking about and positioning herself within the greater world were augmented (Hannaford, 2016). The (im)materialities framework supplied multiple ways to view Rania's experience through her literacy practices, and invited fruitful connections across these differing views, to help me to think about the ways in which Rania might make meaning out of her worlds and develop her own sense of self.

\section{English Expat Edward}

Edward had previously lived in two other mainland European countries and had never lived in England. At the time of the study he was a student in Grade 6. He was the youngest of three sons and looked up to his elder brothers. Edward's parents were separated and maintained an amicable relationship. The three boys lived with their 
English mother, who was employed by a United Nations-affiliated organisation, and were in frequent contact via digital technologies and regular visits with their English father, who was working in the private sector in a neighbouring European country. It was important to Edward's mother to maintain her Englishness, a positioning that she also assumed for her sons. Edward's mother remarked that 'other people say that our house kind of exudes an English attitude to life'.

Proposition 3, 'literacies are materialised in things', provided a way to explore this Englishness in Edward's environment and Edward's positioning towards it. A contributing element may have been Edward's mother subscribing to British newspapers and sports magazines in paper format, and to British television via expensive cable links. According to their mother, being surrounded by British 'stuff' at home provided her sons' with a sense of Englishness. From her perspective, 'very much part of the identity (her sons) wish to acquire is to be proper English lads'. Yet, there were clearly points of departure between Edward's experience, and his mother's perception of Edward's Englishness. A simple example is that while his mother stressed the cultural superiority of English television, Edward's favourite television show was the American programme, The Simpsons. This programme was an important cultural resource for Edward as it was a means to reinforce his bond with his International School friends.

When analysing the ways in which Edward spoke about 'stuff' in his life, it was clear that there was little stuff Edward valued and identified with because of its links with England. And multiple examples of stuff or things Edward valued due to its association with people he cared about. One example of these centres on a cake. The 
cake was baked by Edward and other members of his family, a culturally-infused, literacy-rich event in itself combining recipe text with conversations about baking and prior experience, further emotionally-heightened because the cake was being made for his Grandmother's visit. Edward spoke very fondly of time spent visiting his maternal grandparents in England, and his paternal grandmother's visits to Edward's European home, statements that centred around Edward's fondness of his grandparents, not about the experience being in England or being a part of an extended English community. As with the other children I spoke with, Edward's face-to-face social interaction with his extended family was clearly demarcated by time and place. Edward's heightened emotional attachment to the cake he had baked for his grandmother's visit, seemed to me, a parent to two globally mobile children whose grandparents lived even further away and thus were less regularly met, symbolic of the experience of a globally mobile childhood.

When working with Proposition 4: meaning-making is embodied, I noted that when Edward hesitated while getting his thoughts together, he uttered a polite Englishaccented 'err', rather than saying 'like', the American-influenced 'valleyspeak' commonly used by most other students. This came across as a way in which Edward did embody the Englishness of his H/home environment and stood out from his many friends. By contrast, when working with this lens to consider the constant joy of Edward's everyday life, football, the closeness of Edward's ties to his International community became particularly apparent.

Edward played football on the oval at break time, and when he talked about this time it was with evident joy. In our conversations football was about moving, doing, 
making decisions, and anticipating the decisions of others. Football was a vital, exciting, embodied social practice centred on Edward being in the moment. This was followed through in his digital play on FIFA games, in which the excitement and complexity of the X-box version, which gave him the opportunity to play as, and think as, many players at once, was preferred to the restrictions of playing only one avatar in the public space of the online version.

Edward's football skills had been honed through deliberate effort over time, and he had maintained a high social status among his friends for several years due to his sporting prowess (Hannaford, 2012). He was now too advanced for the Saturday morning international children's football club that had previously been important to his family's social life so, through lack of choice, Edward played competitively with a local team. This meant that, unlike many of the International School children, Edward had the opportunity to make friends in the local community. He spoke the local language with confidence. Yet Edward was not interested in cultivating relationships with members of the local football team. This seemed surprising, as Edward seemed to thrive on extensive social connections, and via Facebook and Skype maintained connections with many boys, from a range of cultural backgrounds, that had moved away from the International School. Edward planned to join the International School football team as soon as he was old enough. The school team would not improve Edward's play, nor offer the potential of the local football club's connections with larger European leagues. Edward's plan reinforced my impression that football was a means through which Edward obtained some control over his social worlds (Hannaford, 2012). His hard-earned skills, accompanied by a wide knowledge on the subject drawn from a range of sources and mediums, earned him an elevated status 
amongst the social group he appeared to invest the most effort into, his globally mobile community of International School peers.

Through the view that Propositions $3 \& 4$ opened up, it seemed that in various ways and degrees ways 'English' was not a subjectivity that Edward actively prioritised, it offered little to further his efforts to be happily socially connected. And, through the view that Propositions $1 \& 2$ made visible, nor did Rania appear to prioritise her Bangladeshi subjectivities, instead exploring and embracing other cultural offerings in her environment. Used with an extensive dataset as I did, the framework presented copious possibilities to locate these children's experiences within sociocultural understandings of literacy practices. It helped illuminate exploratory and/or comfortable and/or preferred sites of $\mathrm{H} /$ home allegiance and belonging in Rania and Edward's lives, during certain moments in time and space. This paper's purpose is to document how I applied the (im)materialities framework to this research, rather than to critique the framework. And the framework was useful for analysing this dataset whilst still foregrounding the children's voices. To achieve this I used the analytical framework with a light hand, embedded within the structure of case studies.

The (im)materiality framework is designed to challenge the notion of rigid divisions between material and immaterial aspects of meaning-making and promote a deeper view of the complexities of literacy practices (Burnett et al, 2014). Multiple ways of viewing any single observed and/or recorded moment, makes a literacy event seem realistically fragmented (Burnett \& Merchant, 2016). In this paper I do not focus on how the four proposals work in interaction within the context of one event. I call selectively on different dimensions of the model to illuminate certain events at certain 
times. Used in this way, the (im)materialities framework still draws attention to the complexities of literacy practices, by building a picture of the diverse and interwoven processes at work across each child's life. By applying these suggested theoretical approaches, the multiple strand analysis led to the desired outcome - a multilayered analysis in which the children's experiences were not oversimplified and their voices remained at the centre of the work. Nonetheless, the mix and layering of the (im)materialities framework aided in the recognition of some overarching conclusions to be taken away from the research.

\section{The contrapuntal lines of $\mathbf{H} / \mathbf{h o m e}$ :}

Drawing from Kwa (2002), Burnett et al (2014) suggest that taking into account the multiple facets of literacy events evokes a perception of their baroque complexity. As my own first forays into the analysis of creative production were within the language of music, my trigger response on reading this analogy was to recall time spent analysing Baroque music. In examples such as the fugues of Bach, multiple separate melodic lines play together as one complex polyphonic whole. These different lines or voices - may be introduced at different times, sometimes solo, sometimes in combination, and typically with some lines being more dominant than others at different points in the music. One way to think of it is as horizontal music, in contrast to a more vertically structured homophonic style in which a single melody is supported by other voices singing in harmony. To conclude this paper, I also borrow from a notion of baroque complexity, but from a differently focussed musical illustration, to present a macro view of these globally mobile children's lines of allegiance and belonging with regards to $\mathrm{H} / \mathrm{home}$. 
With the benefit of the perspectives that the (im)materialities framework afforded, it became possible to understand more deeply the ways in which Rania and Edward, as with other globally mobile children in the study, drew on $\mathrm{H} / \mathrm{home}$ voices from the country(s) their parents' hail from, and the country(s) they themselves lived in at periods of their life, and from other lines of allegiance and belonging available to them, such as the spaces, peoples and cultures of football or those found in the privacy of digital worlds. A fugal/contrapuntal metaphor can then be used as a way to think about these globally mobile children's lives, and to illustrate the lines of allegiance and belonging which enter their lives at different times, and from different places, with varying degrees of dominance. In this analogy, a life experience involving one strongly defined singular national allegiance shared with an extended family living in the same country may, as a contrast, be thought more like a homophonic composition, in which one unified melodic line dominates. Children like Rania and Edward have a different life expereince from this, and the question 'where is home?', is complex, somewhat akin to the lines of music that gradually enter a fugue and perhaps build to a complex polyphony. Through the view that the four propositions the (im)materialities framework provided of the literacy practices in Rania and Edward's lives, it seemed that for these globally mobile children, multiple lines of belonging and allegiance came together to form a complex (well)tempered whole.

\section{References}

Anderson, B. (1983). Imagined Communities: Reflections on the Origin and Spread of Nationalism. London/ New York: Verso. 
Bilgin, P. (2016). “Contrapuntal Reading” as a Method, an Ethos, and a Metaphor for Global IR. International Studies Review, 18(1), 134-146.

Burnett, C. (2014). Investigating Pupils Interactions Around Digital Texts: A Spatial Perspective on the "Classroom-ness" of Digital Literacy Practices in Schools. Educational Review, 66(2), 192-209.

Burnett, C., \& Merchant, G. (2016). Boxes of poison: baroque technique as antidote to simple views of literacy. Journal of Literacy Research. 48(3), 258-279.

Burnett, C., Merchant, G., Pahl, K., \& Rowsell, J. (2014). The (Im)materiality of Literacy: the Significance of Subjectivity to New Literacies Research. Discourse: Studies in the Cultural Politics of Education, 35(1), 90-103.

Comber, B. (2015). Literacy, Place and Pedagogies of Possibility. Retrieved from https://www.youtube.com/watch?v=4-eYFc8mi7o

Hall, S. (2013). The Work of Representation. In S. Hall, J. Evans, \& S. Nixon (Eds.), Representation (2 ed., pp. 1-47). London: Open University/Sage.

Hannaford, J. (2012). Imaginative Interaction with Internet Games. For Children \& Teachers. Literacy, 46(1), 25-32.

Hannaford, J. (2016). Digital worlds as sites of belonging for Third Culture Kids: A New Literacies perspective. Journal of Research in International Education, 15(3), 253-265.

Hayden, M. (2011). Transnational Spaces of Education: The Growth of the International School Sector. Globalisation, Societies and Education, 9(2), 211-224.

Hayden, M. (2012). Third Culture Kids: The Global Nomads of Transnational Spaces of Learning. In R. Brooks, A. Fuller, \& J. Waters (Eds.), Changing Spaces of Education: New Perspectives on the Nature of Learning (pp. 59-78). London/ New York: Routledge. 
Kress, G. (2003). Literacy in the new media age. London: Routledge.

Kress, G., \& van Leeuwen, T. (2006). Reading Images, The Grammar of Visual Design (2 ed.). Abingdon, Oxon: Routledge.

Kwa, C. (2002). Romantic and Baroque Conceptions of Complex Wholes in the Sciences. In J. Law (Ed.), Complexities: Social Studies of Knowledge Practices (pp. 22-52). Durham; London: Duke University Press.

Law, J. (2004). And If the Global Were Small and Incoherent? Method, Complexity, and the Baroque. Society and Space, 22(1), 22-26.

Leander, K., \& Sheehy, M. (2004). Spatializing Literacy Research and Practice. New York: Peter Lang.

Lefebvre, H. (1991). The Production of Space (D. Nicholson-Smith, Trans.). Oxford: Blackwell.

Lemke, J. L. (2013). Thinking About Feeling: Affect Across Literacies and Lives. In O. Erstad \& J. Sefton-Green (Eds.), Identity, Community, and Learning Lives in the Digital Age (pp. 57-69). Cambridge: Cambridge University Press.

Miller, D. (2008). The Comfort of Things. Cambridge, UK: Polity Press.

Miller, D. (2010). Stuff. Cambridge: Polity.

Mills, K. A. (2015). Literacy Theories for the Digital Age: Multilingual Matters.

Mills, K. A., \& Comber, B. (2013). Space, Place, and Power. In K. Hall, T. Cremin, B. Comber, \& L. Moll (Eds.), International Handbook of Research on Children's Literacy, Learning, and Culture. Oxford: John Wiley \& Sons.

Nette, J., \& Hayden, M. (2007). Globally Mobile Children: The Sense of Belonging. Educational Studies, 33(4), 435-444. 
Pahl, K., \& Rowsell, J. (2010). Artifactual Literacies: Every Object Tells a Story. New York: Teachers College Press.

Pink, S. (2011). Multimodality, multisensoriality and ethnographic knowing: social semiotics and the phenomenology of perception. Qualitative Research, 11(3), 261-276.

Pollock, D. C., \& Reken, R. v. (2009). Third Culture Kids: The Experience of Growing Up Among Worlds. Boston: Nicholas Brealey Publishing.

Said, E. (1984). Reflections on Exile. Granta, 13(Autumn), 157-172.

Said, E. (1993). Culture and imperialism. New York: Knopf/Random House.

Sears, C. (2011). Integrating Multiple Identities: Narrative in the Formation and Maintenance of the Self in International School Students. Journal of Research in International Education, 10(1), 71-86.

Soja, E. W. (1996). Thirdspace: Journeys to Los Angeles and Other Real-andImagined Places. Oxford: Wiley-Blackwell.

Stake, R. E. (2006). Multiple Case Study Analysis. New York; London: Guilford Press.

Symes, C. (2006). The Paradox of the Canon: Edward W. Said and musical transgression. Discourse: Studies in the Cultural Politics of Education, 27(3), 309-324.

Useem, J., Useem, R., \& Donoghue, J. (1964). Men in the Middle of the Third Culture. The International Executive, 6(1), 17-18.

Walker, G. (2012). Tea and Oysters: Metaphors for a Global Education. International School's Journal, XXXI(2), 9-18. 